\title{
Low-intensity ultrasound-induced cellular destruction and autophagy of nasopharyngeal carcinoma cells
}

\author{
PING WANG ${ }^{1}$, ALBERT WINGNANG LEUNG ${ }^{2}$ and CHUANSHAN XU ${ }^{2,3}$ \\ ${ }^{1}$ Department of Ultrasound Medicine, The Affiliated Hospital of North Sichuan Medical College, Sichuan; \\ ${ }^{2}$ School of Chinese Medicine, The Chinese University of Hong Kong, Hong Kong SAR; ${ }^{3}$ Department of Photodynamic \\ and Sonodynamic Therapy, Second Affiliated Hospital, Chongqing Medical University, Chongqing, P.R. China
}

Received June 8, 2011; Accepted July 1, 2011

DOI: $10.3892 /$ etm.2011.317

\begin{abstract}
Ultrasound therapy, as a non-invasive modality, has been attracting extensive attention in the management of malignant tumors. The present study aimed to investigate low-intensity ultrasound-induced cellular destruction and autophagy in nasopharyngeal carcinoma cells in vitro. Nasopharyngeal carcinoma CNE2 cells were subjected to ultrasound exposure, as tumor model cells, at an intensity of $1.35 \mathrm{~W} / \mathrm{cm}^{2}$. Cytotoxicity was investigated $24 \mathrm{~h}$ after ultrasound treatment. Nuclear damage was observed using nuclear staining with Hoechst 33258. Mitochondrial dysfunction was measured using confocal laser scanning microscopy with rhodamine123 staining. Mitochondrial morphology and autophagy were observed using transmission electron microscopy (TEM). Low-intensity ultrasound significantly killed CNE2 cells proportional to the ultrasonic treatment time. Upon nuclear staining, nuclear condensation and typical apoptotic bodies were noted in the CNE2 cells exposed to ultrasound wave for $12 \mathrm{sec}$. A collapse in mitochondrial membrane potential was noted in the treated cells. Upon TEM, swollen mitochondria, more vacuoles and autophagy were noted after ultrasound treatment. Our findings demonstrate that low-intensity ultrasound significantly damages CNE2 cells and emphasize that autophagy may be an important event in ultrasound-induced cell death.
\end{abstract}

\section{Introduction}

Nasopharyngeal carcinoma (NPC) is one of the most common malignant tumors in Southeast Asia, including Hong Kong. Current treatments for NPC, such as surgery, radiotherapy and chemotherapy, have serious side effects with limited success (1-4). Fortunately, continued research efforts have spawned novel therapies.

Correspondence to: Dr Chuanshan Xu, School of Chinese Medicine, The Chinese University of Hong Kong, Shatin, N.T. Hong Kong SAR, P.R. China

E-mail: xcshan@163.com

Key words: ultrasound treatment, autophagy, nasopharyngeal carcinoma
With the development of transducer design and measurement technology, ultrasound as a safe alternative and non-invasive therapeutic approach has been widely applied in medicine (5). High-intensity focal ultrasound (HIFU) produces a high temperature that directly or indirectly deactivates tumor cells/tissues and is therefore undergoing development as a noninvasive therapeutic modality in the management of cancer (6). Recently, the applications of low-intensity ultrasound in tumors and vascular diseases have been widely investigated. Emerging evidence has confirmed that low-intensity ultrasound markedly inhibits the proliferation and clone formation of tumor cells through heat, mechanical effects and acoustic cavitation $(7,8)$. Fitzgerald et al demonstrated that therapeutic ultrasound markedly decelerated cellular proliferation and decreased in-stent hyperplasia (9). Takeuchi et al reported that ultrasound energy inhibits the proliferation of mouse $\mathrm{T}$ lymphoma cells at an intensity of $350 \mathrm{~mW} / \mathrm{cm}^{2}$ and human histiocytic lymphoma cells (U-937) at an intensity of $700 \mathrm{~mW} /$ $\mathrm{cm}^{2}$. The morphological changes included apoptosis, such as the shrinking of cells and formation of apoptotic bodies (10). However, it remains unclear which types of mechanisms are involved in these bioeffects. Recent studies have shown that autophagy is involved in the pathogenesis of tumors. The induction of autophagy has shown a substantial improvement in antitumor therapy $(11,12)$. The present study focused on investigating low-intensity ultrasound-inducing cellular destruction and autophagy in NPC cells in vitro.

\section{Materials and methods}

Cell culture. The CNE2 NPC cell line was provided by the Shanghai Biology Institute under the approval of the Ethics Committee of Chongqing Medical University. The cells were grown in RPMI-1640 medium supplemented with $10 \%$ fetal calf serum (FCS; Gibco), $50 \mu \mathrm{g} / \mathrm{ml}$ penicillin, $50 \mu \mathrm{g} / \mathrm{ml}$ streptomycin and $10 \mu \mathrm{g} / \mathrm{ml}$ neomycin. The cells were incubated at $37^{\circ} \mathrm{C}$ in a humidified $\mathrm{CO}_{2}(5 \%)$ incubator.

Ultrasound treatment. An ultrasound exposure system, which was equipped with a built-in digital timer and intensity regulator, was manufactured by Southwest University, Chongqing, China. In this system, a 1-cm diameter plane transducer from piezoelectric ceramic was used to convert the electrical power 
into acoustic power. Prior to ultrasound exposure, polyacetylene test tubes containing a $1-\mathrm{ml}$ cell suspension $\left(1 \times 10^{6}\right.$ cells/ $\mathrm{ml}$ ) was fixed vertically on a platform in a water tank filled with degassed water with the ultrasound beam pointing upward as described by Yu et al (13). In this study, CNE2 cells were exposed to continuous ultrasound with a frequency of $1.7 \mathrm{MHz}$, and the spatial average intensity was set to $1.35 \mathrm{~W} / \mathrm{cm}^{2}$. The cells used in the experiments were randomly divided into two groups: ultrasound treatment and control. The cells in the control group were not treated with ultrasound treatment.

Cytotoxicity. The cytotoxic effect of ultrasound on the CNE2 cells was evaluated using the 3-(4,5-dimthylthiazol-2-yl)-2,5 diphenyl-tetrazolium bromide (MTT) assay. Briefly, the treated cells $\left(5 \times 10^{3}\right.$ cells/well) were incubated in a 96-well microplate at $37^{\circ} \mathrm{C}$ for $20 \mathrm{~h}$. The medium was then removed from each well, and $100 \mu \mathrm{l}$ MTT reagent was added to each well $(0.5 \mathrm{mg} /$ $\mathrm{ml}$, diluted with medium), and then incubation was carried out for $4 \mathrm{~h}$ at $37^{\circ} \mathrm{C}$. Finally, MTT reagent was removed, and $100 \mu \mathrm{l}$ dimethyl sulfoxide (DMSO) was added per well. After shaking for $10 \mathrm{~min}$, the optical density (OD) was measured using an iEMS Analyzer (Type1401; Lab-system) at a wavelength of $570 \mathrm{~nm}$. The percentage of cytotoxicity was calculated using the following equation: Cytotoxicity $(\%)=(\mathrm{OD}$ control group - OD treatment group)/OD control group x 100\%.

Nuclear staining. The treated CNE2 cells $\left(1 \times 10^{5}\right.$ cells/well $)$ were incubated at $37^{\circ} \mathrm{C}$ for $18 \mathrm{~h}$ after ultrasound treatment. The cells were washed with phosphate-buffered solution (PBS) and then stained with Hoechst $33258(5 \mu \mathrm{g} / \mathrm{ml})$ (stock solution $1 \mathrm{mg} / \mathrm{ml}$ in sterile water) for $5 \mathrm{~min}$ at $37^{\circ} \mathrm{C}$. The stained cells were washed with PBS two times and then observed immediately using fluorescence microscopy. A filter set of Ex/ Em of BP330-380/LP420 nm was used, and the images were recorded by a color charge-coupled device camera.

Confocal laser scanning microscopy. The mitochondrial membrane potential $(\Delta \Psi \mathrm{m})$ was measured using confocal laser scanning microscopy (CLSM) with rhodamine123 staining. Briefly, CNE2 cells were treated with ultrasound for $12 \mathrm{sec}$ at an ultrasonic intensity of $1.35 \mathrm{~W} / \mathrm{cm}^{2}$, and were further incubated for $4 \mathrm{~h}$. The rhodamine123 (dissolved in DMSO to produce a $1 \mathrm{mg} / \mathrm{ml}$ stock solution) $(5 \mu \mathrm{g} / \mathrm{ml})$ was added $30 \mathrm{~min}$ before cell harvesting. After being washed with PBS, the cells were observed using CLSM (LSM 510; Zeiss, Esslingen, Germany) with the excitation setting at $488 \mathrm{~nm}$.

Transmission electron microscopy. Transmission electron microscopy (TEM) was performed to identify mitochondrial morphological changes and autophagy of the CNE2 cells $18 \mathrm{~h}$ after ultrasound exposure. Fixed cells were post-fixed in $2 \% \mathrm{OsO}_{4}$, dehydrated in graded alcohol and flat embedded in Epon 812 (Electron Microscopy Sciences, Fort Washington, PA, USA). Ultra-thin sections (100 nm) were prepared, stained with uranyl acetate and lead citrate, and examined under an electron microscopy (H-600; Hitachi, Japan).

Statistical analysis. All data were processed using one-way analysis of variance (ANOVA). A P-value of $<0.05$ was considered to indicate a significant difference.

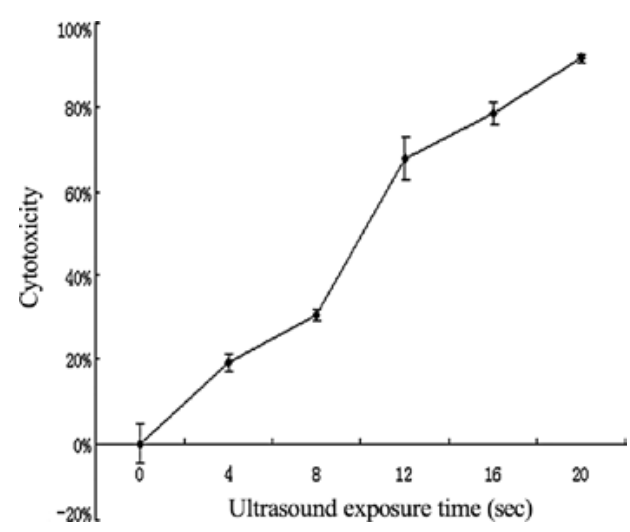

Figure 1. Cytotoxic effect of ultrasound on CNE2 cells $24 \mathrm{~h}$ after ultrasound exposure was assessed by MTT assay. The frequency of ultrasound was $1.7 \mathrm{MHz}$ and the spatial average ultrasonic intensity was set at $1.35 \mathrm{~W} / \mathrm{cm}^{2}$.

\section{Results}

Cytotoxicity of ultrasound in CNE2 cells. To assess the cytotoxicity of ultrasound in the CNE2 NPC cell line, the ultrasound-treated cells were incubated for $24 \mathrm{~h}$. The cytotoxic effect of ultrasound on the CNE2 cells is shown in Fig. 1. The death rate of CNE2 cells exposed to ultrasound $(1.7 \mathrm{MHz})$ at $1.35 \mathrm{~W} / \mathrm{cm}^{2}$ was significantly higher compared to the death rate of CNE2 cells in the absence of ultrasound exposure $(\mathrm{P}<0.05)$. The death rate increased along with the ultrasound exposure time, showing that ultrasound treatment definitively killed CNE2 cells.

Nuclear damage. The CNE2 cells were stained using Hoechst 33258 after ultrasound treatment, and normal cells displayed a weak fluorescence as shown in Fig. 2A. As shown in Fig. 2B, nuclear condensation and fragmentation were observed in the cells $18 \mathrm{~h}$ after ultrasound treatment.

Confocal laser scanning microscopy. CLSM analysis with rhodamine123 staining was used to measure the mitochondrial membrane potential (MMP). A significant collapse of MMP was noted in the CNE2 cells after the treatment of ultrasound (Fig. 3).

Transmission electron microscopy. TEM showed the integrity of cell membranes and many normal mitochondria in the CNE2 cells $18 \mathrm{~h}$ after sham treatment (Fig. 4A). After ultrasound treatment, swollen mitochondria, vacuoles and autophagosomes were noted in the treated cells (Fig. 4B). This demonstrated that ultrasound significantly results in the ultrastructural damage and induced autophagy of CNE2 cells.

\section{Discussion}

Ultrasound therapy, as a non-invasive modality, has shown promise as a novel technique in the management of tumors $(5,6)$. To investigate the effect of low-intensity ultrasound on NPC cells, the poorly differentiated CNE2 cell line was chosen as tumor model cells for cytotoxic assay $24 \mathrm{~h}$ after ultrasound exposure in the present study. The results showed time-dependent cytotoxicity in CNE2 cells after ultrasound 
A

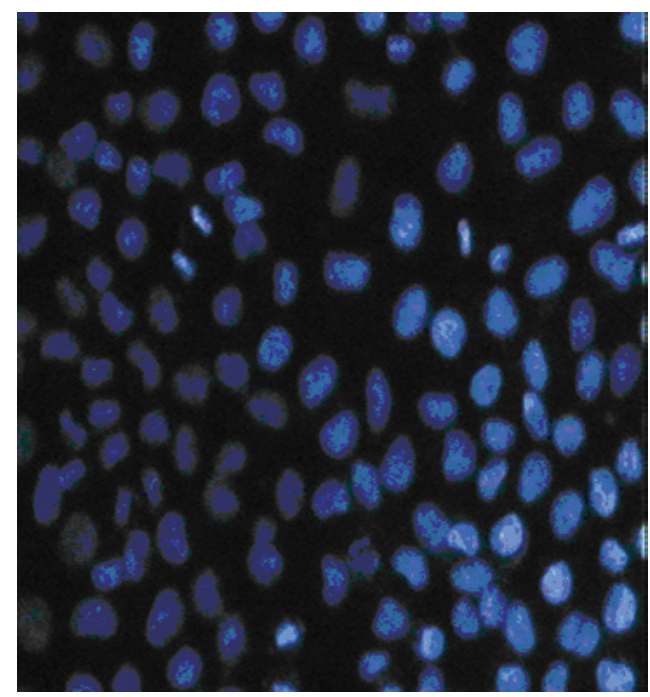

B

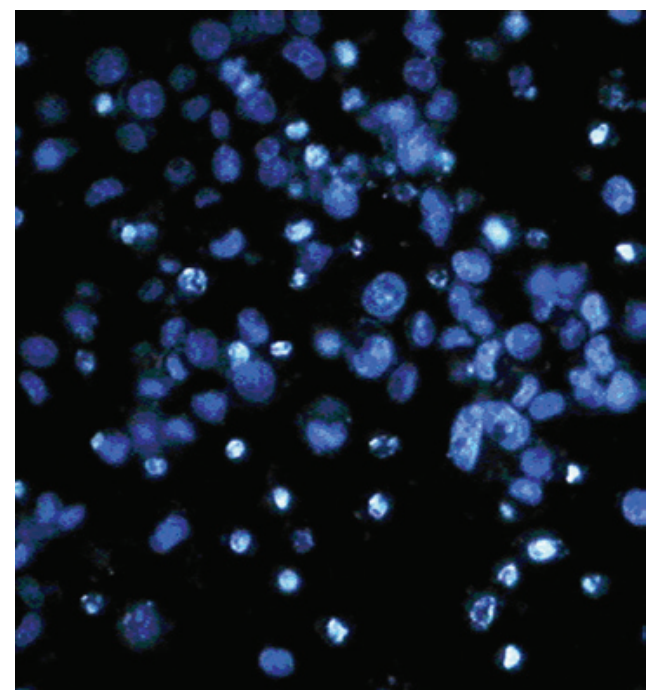

Figure 2. Nuclear damage in CNE2 cells $18 \mathrm{~h}$ after ultrasound treatment was analyzed by the Hoechst 33258 staining method. (A) Control. (B) Ultrasound treatment.

A

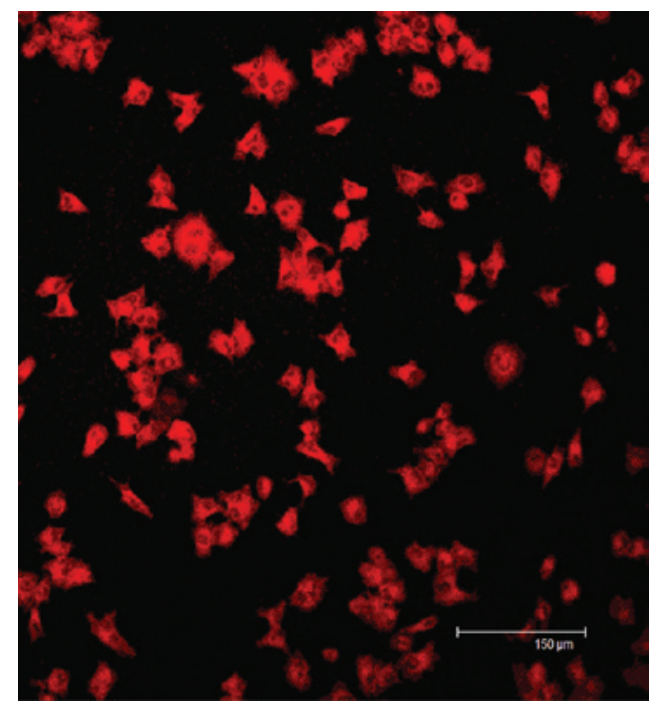

B

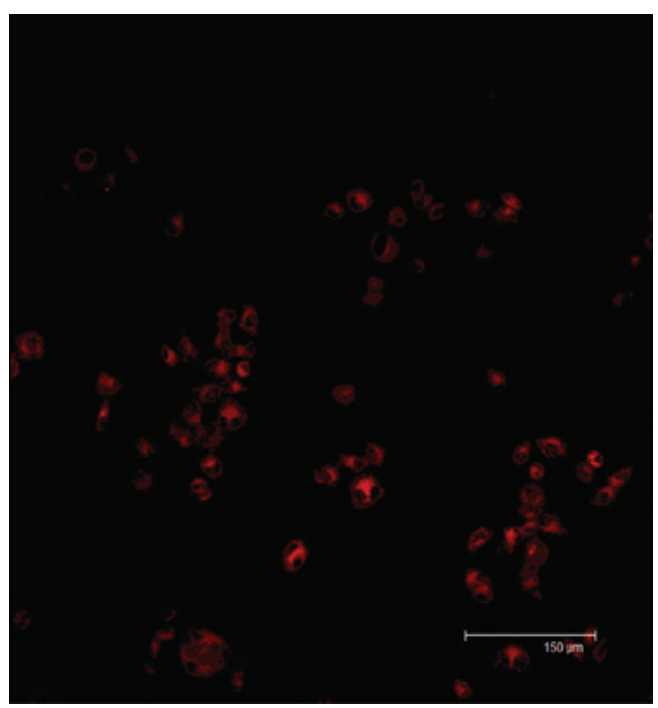

Figure 3. Collapse of MMP in CNE2 cells demonstrated by confocal laser scanning microscopy with rhodamine123 staining $4 \mathrm{~h}$ after ultrasound treatment. (A) Control. (B) Ultrasound treatment. Bar, $150 \mu \mathrm{m}$.

A

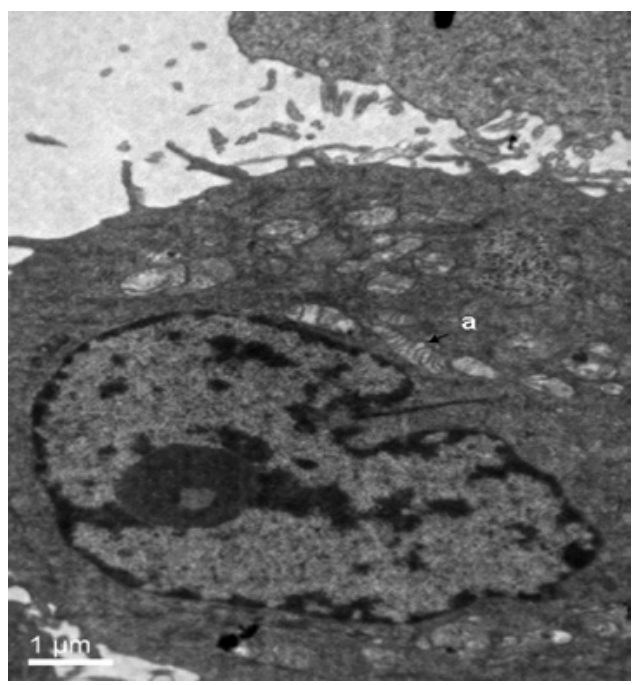

B

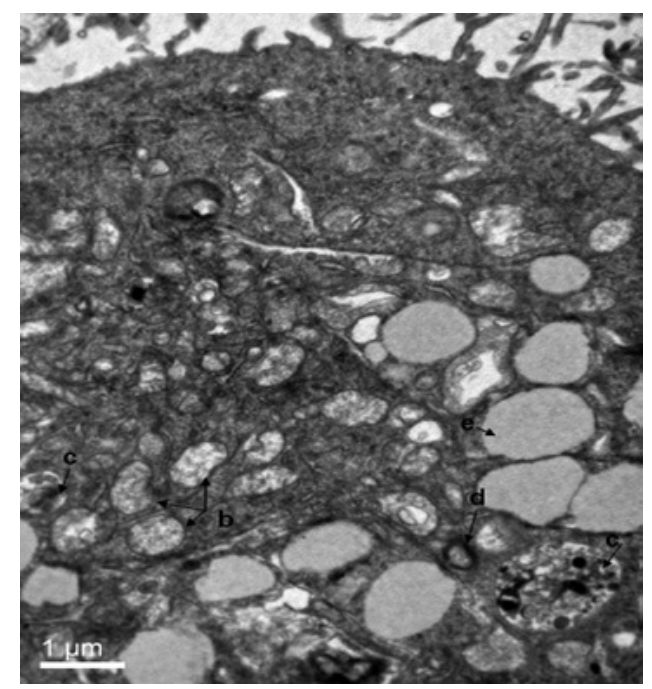

Figure 4. Investigation of ultrastructural morphology and autophagy of CNE2 cells using TEM at $18 \mathrm{~h}$ after ultrasound treatment. (A) Control. (B) Ultrasound treatment. a, normal mitochondrion; b, swollen mitochondria; c, autophagosome; d, mitochondrial myelin-like body; e, vacuole. Magnification, x20,000. 
exposure at the intensity of $1.35 \mathrm{~W} / \mathrm{cm}^{2}$. These findings revealed that low-intensity ultrasound markedly killed NPC cells. However, the underlying mechanisms are still unclear.

Structural and/or functional changes always occur in biological tissues upon exposure to ultrasound. The structural changes range from slight damage to cell death (6). The degree of structural and/or functional damages and the ability of the cells to repair the damages determine the mode of cell death, which manifests as instant lysis, necrosis or apoptosis (6). Lysis and necrosis consist of a passive route which usually triggers rigorous inflammation, directly resulting in cell death. Apoptosis, a carefully regulated mode of cell death involving reduced immune reaction, is a preferred mode of killing cancer cells (11). In this study, typical apoptotic characteristics, such as nuclear condensation and fragmentation, were observed $18 \mathrm{~h}$ after treatment with low-intensity ultrasound. A significant collapse of MMP was concomitantly observed in CNE2 cells after treatment with low-intensity ultrasound as determined by CLSM with rhodamine123 staining. The collapse of MMP is an early event in the process of apoptosis (14). Therefore, our findings demonstrated that low-intensity ultrasound significantly induced apoptosis of CNE2 cells.

In our TEM, swollen mitochondria and vacuoles were found in the cells treated with low-intensity ultrasound, demonstrating that low-intensity ultrasound significantly damages mitochondrial structure. Additionally, CLSM showed that low-intensity ultrasound markedly decreases the fluorescent intensity value of rhodamine123. The fluorescent intensity value of rhodamine123 reflects MMP and the functions of mitochondria $(15,16)$. These findings indicate that low-intensity ultrasound causes the damage of mitochondrial morphology and function. Mitochondrial damage directly affects cellular energy metabolism, cell activity and even cell death $(16,17)$. At the same time, autophagosomes were observed in the cells treated with low-intensity ultrasound. This suggests that low-intensity ultrasound induces the autophagy of CNE2 cells. Autophagy is an evolutionarily degradative mechanism that is essential for growth regulation and maintenance of homeostasis in all eukaryotic cells $(18,19)$. Defective autophagy causes a variety of diseases, including malignant tumors $(19,20)$. Basal levels of autophagy may act as a tumor-suppressor mechanism. Autophagic induction is regarded by several researchers as an important strategy for treating cancer (12). Conversely, multiple lines of evidence indicate that autophagic occurrence may also permit the survival of cancer cells in response to external stress or cytotoxic drugs (20). Therefore, it is unclear whether autophagy induces the death of CNE2 cells or promotes their survival after treatment with low-intensity ultrasound. The exact mechanism should be determined in future investigations.

In summary, the present study demonstrated that low-intensity ultrasound significantly damages CNE2 cells. Our results emphasize that autophagy may be an important event in ultrasound-induced cell death.

\section{Acknowledgements}

This study was supported by grants from the National Nature Science Foundation of China (30973168) and the Chinese University of Hong Kong (2030408). The authors would also like to express sincere thanks to Mr. Eric Chuck Hey Pun, Mr. Guoyang Li, Mr. Jianyong Wu, Mr. Jingchuan Fan and Mr. Kejian Wang for the helpful assistance.

\section{References}

1. Lin YT, Wang LF and Hsu YC: Curcuminoids suppress the growth of pharynx and nasopharyngeal carcinoma cells through induced apoptosis. J Agric Food Chem 57: 3765-3770, 2009.

2. Wang X, Xia X, Xu C, et al: Ultrasound-induced cell death of nasopharyngeal carcinoma cells in the presence of curcumin. Integr Cancer Ther 10: 70-76, 2011.

3. Wang P, Xu CS, Xu J, Wang X and Leung AW: Hypocrellin B enhances ultrasound-induced cell death of nasopharyngeal carcinoma cells. Ultrasound Med Biol 36: 336-342, 2010.

4. Wang P, Xu C, Xia X, Xu J, Wang X, Xiang J and Leung AW: Mitochondrial damage in nasopharyngeal carcinoma cells induced by ultrasound radiation in the presence of hypocrellin B. J Ultrasound Med 29: 43-50, 2010.

5. Tian Z, Quan X, Xu C, Dan L, Guo H and Leung W: Hematoporphyrin monomethyl ether enhances sonokilling action of ultrasound on osteosarcoma in vivo. J Ultrasound Med 28: 1695-1702, 2009.

6. Hundt W, Yuh EL, Steinbach S, Bednarski MD and Guccione S: Comparison of continuous vs. pulsed focused ultrasound in treated muscle tissue as evaluated by magnetic resonance imaging, histological analysis, and microarray analysis. Eur Radiol 18: 993-1004, 2008.

7. Yu T, Wang Z and Mason TJ: A review of research into the uses of low level ultrasound in cancer therapy. Ultrason Sonochem 11: 95-103, 2004.

8. Alter A, Rozenszajn LA, Miller HI and Rosenschein U: Ultrasound inhibits the adhesion and migration of smooth muscle cells in vitro. Ultrasound Med Biol 24: 711-721, 1998.

9. Fitzgerald PJ, Takagi A, Moore MP, et al: Intravascular sonotherapy decreases neointimal hyperplasia after stent implantation in swine. Circulation 103: 1828-1831, 2001.

10. Takeuchi S, Udagawa Y, Oku Y, Fujii T, Nishimura $\mathrm{H}$ and Kawashima N: Basic study on apoptosis induction into cancer cells U-937 and EL-4 by ultrasound exposure. Ultrasonics 44: e345-e348, 2006.

11. Feril LB Jr, Kondo T, Cui ZG, et al: Apoptosis induced by the sonomechanical effects of low intensity pulsed ultrasound in a human leukemia cell line. Cancer Lett 221: 145-152, 2005.

12. Sasnauskene A, Kadziauskas J, Vezelyte N, Jonusiene VM and Kirveliene V: Apoptosis, autophagy and cell cycle arrest following photodamage to mitochondrial interior. Apoptosis 14: 276-286, 2009.

13. Yu T, Hu K, Bai J and Wang Z: Reversal of adriamycin resistance in ovarian carcinoma cell line by combination of verapamil and low-level ultrasound. Ultrason Sonochem 10: 37-40, 2003.

14. Susin SA, Lorenzo HK, Zamzami N, et al: Molecular characterization of mitochondrial apoptosis-inducing factor. Nature 397: 441-446, 1999.

15. Wang Y, Che C, Chiu J and He Q: Dioscin (saponin)-induced generation of reactive oxygen species through mitochondria dysfunction: a proteomic-based study. J Proteome Res 6: 4703-4710, 2007.

16. Shen Z, Shen J, Li Q, Chen C, Chen J and Zeng Y: Morphological and functional changes of mitochondria in apoptotic esophageal carcinoma cells induced by arsenic trioxide. World J Gastroenterol 8: 31-35, 2002.

17. Lee HC, Yin PH, Lu CY, Chi CW and Wei YH: Increase of mitochondria and mitochondrial DNA in response to oxidative stress in human cells. Biochem J 348: 425-432, 2000.

18. Li J, Hou N, Faried A, Tsutsumi S, Takeuchi T and Kuwano H: Inhibition of autophagy by 3-MA enhances the effect of 5-FU-induced apoptosis in colon cancer cells. Ann Sur Oncol 16: 761-771, 2009.

19. Ito S, Koshikawa N, Mochizuki S and Takenaga K: 3-methyladenine suppresses cell migration and invasion of HT1080 fibrosarcoma cells through inhibiting phosphoinositide 3 -kinanses independently of autophagy inhibition. Int J Oncol 31: 261-268, 2007.

20. Lu Z, Luo RZ, Lu Y, et al: The tumor suppressor gene ARHI regulates autophagy and tumor dormancy in human ovarian cancer cells. J Clin Invest 118: 3917-3929, 2008. 